\title{
Student's Perception and Attitudes toward Public Health Profession and National Competency Examination
}

\author{
By Lafi Munira
}




\title{
Student's Perception and Attitudes toward Public Health Profession and National Competency Examination
}

\author{
Lafi Munira, Lina Handayani
}

Faculty of Public Health, Universitas Ahmad Dahlan, Yogyakarta, Indonesia

\section{Article Info \\ Article history: \\ Received March 28, 2014 \\ Revised April 28, 2014 \\ Accepted May 21, 2014}

\section{Keyword:}

Perceptions

Attitudes

Public health

Competencies

Examination

\begin{abstract}
One form of quality assurance is convening public health's national competencies examination in academic phase which is conducted before students graduate from university. The purpose of this study to determine students's perceptions and attitudes ab 7 public health's profession and national competencies examination. The design of this study was descriptive qualitative employed case study approach. Focus group discussion was used to collect data. Data were analyzed by content analysis.Students felt less confident about their identity profession so that requires motivation by lecturer. Students expressed the need to improve public health graduates's competencies since academic phase. National competencies examination is important to do as a solution to guarantee the graduates's quality. Implementation of the competencies test is needed to consider aspects of management and technical readiness. National competencies examination is a tool that could proves the identity of public health graduates's competencies. Everyone with a public health background should know that there will be a competency test then they should prepare it properly.
\end{abstract}

3

Copyright $@ 2014$ Institute of Advanced Engineering and Science. All rights reserved.

Corresponding Author:

Lina Handayani,

Faculty of Public Health,

Universitas Ahmad Dahlan,

Prof. Soepomo Street, Umbulharjo 55164, Yogyakarta, Indonesia.

Email: linafkm@gmail.com

\section{INTRODUCTION}

Public health education is currently showing the amount of interest for learners are likely continue to increase. This fact is a form of public awareness of the importance of health needs as a science, as well as promising areas of work in the future. Along with that, the number of public health institute 10 increased moldy in various regions, and realized that the growth has not been accompanied by a number of improvements in the quality of education, educational orientation varies and is often considered more distant from expectations [1].

The conditions mentioned above will not produce learning outcomes (learning outcomes) with the expected abili 6 to answer the needs of professional public health efforts. At the same time, the challenges of globalization such as the ASEAN Free Trade Area (AFTA) and World Trade Organization (WTO) in which public health workers from foreign countries can also compete in our country with the quality of public health personnel standardized [1] The quality of public health services is largely determined by the quality of the health personnel who have previously completed education at each institution. It needs a quality assurance system of higher education graduates that can guarantee the quality of healthcare for health workers produced [1].

Every student who has completed his education must take the exam organized by the educational unit accredited education provider or training institutions that are part of the quality assurance system of

8 
higher health education and competence of health workers in Indonesia. One form of quality assurance is convening competency test for each health profession. Competency test is a process to measure the knowledge, skills, and attitudes of health personnel in accordance with established professional standards [2].

Diversity patterns of institutional management of education and the number of health education institutions are very much a particular challenge for Indonesia to maintain the quality of its graduates. Until now, the competency test has been applied to doctors and dentists who have been in progress since 2007, while for other health professionals, the competency test is being developed, particularly the public health and obstetrics [2].

Competency test should be held for any students who have completed education in its path as a form of quality assurance of graduates 9 rom higher health education and competence of health workers in Indonesia, given the globalization of the health sector is an opportunity to improve the quality of health workers so as to improve the quality of health care and quality of health workers in order to compete with foreign health workers who will work in Indonesia as well as in global market [2].

Remind the importance of the implementation of the competency test is nationally uniform and standardized to ensure the competence of their graduates in professional duties, it is necessary to review the extent to which perceptions and attitudes of students about the profession and public health competency test.

\section{2}

\section{RESEARCH METHOD}

This research was descriptive qualitative. This study focused on student perceptions and attitudes about the profession and public health competency test. The study took place at the Faculty of Public Health, Ahmad Dahlan University, implemented starting in July 2013 and ended in January 2014. Subjects i 2 his study were seven public health students Ahmad Dahlan University. Data collection technique was focus group discussions (FGD).

The research instruments used in this study were: 1) FGD's Guide to open discussions with the research subjects; 2) Stationery, record sheet, recorders and cameras to support the FGD process with informants (research subjects). The variables used in this study are students' perceptions about the profession and public health competency tests and student attitudes about the profession and public health competency test. Data analysis was employing a semiotic engineering approach to content analysis. The validity of data was checked by triangulation.

\section{RESULTS AND ANALYSIS}

\subsection{Student Perceptions of professional identity as a public health worker}

In the process of becoming health professionals, students develop beliefs and attitudes about their profession. Students develop an understanding of the limits of their profession, and the ways in which they can interact with others as part of the healthcare team. Unity between beliefs, attitudes and understanding of their role, in the context of work, generally refers to their ' professional identity '

The informant explained that public health personnel is important, because they can analyze the necessary sharply to policy-making, and can also be a leader in the health sector so must knowing many sciences. The informant also asserted that employment is still ambiguous and not in accordance with scientific possessed. Obscurity or mismatch employment land employment in the health sector can be caused due to the extent of employment of public health, in addition to the public health has a broad scope of knowledge to be learned, so that graduates of public health must be prepared if placed at any position in the health sector.

".. people say that public health graduates as just like the doctor, people asked how to cure not how to prevent .." (I3)

Concerns about the lack of public recognition, and the shadows of other professions repeated many times by informants of this study. Based on these findings there are researchers interpret that informants feel less confident because of the lack of public recognition, low self-esteem, pessimistic and less motivated as public health student because it is not their first choice when applying to become a student in university, they didn't know what is the essence of public health and the prospect of working in front of the public health.

One aspect of the learner to consider is the confidence (self-confidence), which is one of the capital in a life that must be grown on any self learners so that later they can be a man who is able to control the 4

IJPHS Vol. 3, No. 2, June 2014: $137-142$ 
various aspects that exist in itself, with the ability the students will be more clear in setting personal goals and objectives are clear, it will be better able to direct behavior toward success [3]. Thus confidence can increase student interest in learning about public health and the desire and passion to know the competencies of public health education.

Self-confidence is a state in the one that contains the strengths, abilities and skills of a person. With a lack of confidence, low self-esteem will dominate a person in their life, and they will grow into a pessimist. Without a sense of confidence that is firmly embedded in the learners' souls, pessimism and low self-esteem will be able to know it with ease. Confidence is something that is valuable. By having confidence, one can do anything with the confidence that it would succeed, if they fail they still has the spirit, remains to be realistic, and then try again with a steady [3]. Based on the research findings, there was an expectation that public health education can be develop better in the future with the competency test.

\subsection{The attitude of students about professional identity as a public health worker}

According to informants, public health should strengthen the position so that it can run a synergistic and integrated with other health pillars, curative and rehabilitative. According to the informant competency is a must-have capability for work performance. Competence is a set of knowledge, skill, and attitudes that must be owned, lived, ruled, and realized by a person in carrying out the duties of professionalism without leaving aspects of personality and social skills abilities in carrying out his duties. Competence of health professionals is the ability to know the subject matter is broad and deep that can be applied to everyday tasks [4].

According to the informant must be competent public health graduates and master the competencies needed to complete the total in work and public recognition. Competencies that need to be owned by the public health graduates is very broad, not only hardskills but also includes soft skills. According to informants, public health is needed because it can analyze the health condition sharply to an input to stakeholders who make health policy. In addition to the public health can be said to be the leader of many science graduates must understand not only knew one aspect of science.

Hardskills previous statements regarding the translation of the text in line with the academic education of public health, the public health education competency standards ar the minimum competencies that must be achieved in public health gf 1 uate education consisting of : 1) the ability to conduct a study and analysis ( Analysis and Assessment ), 2 ) ability to develop policies and programs prerencanaan health ( Policy development and program planning), 3 ) the ability to carry out communication ( communication skills), 4 ) the ability to understand the local culture ( cultural competency / local wisdom), 5 ) the ability to conduct pul 1ic development ( public dimensions of practice ), 6 ) understand the basics of public health sciences ( basic public health sciences), 7 ) ability to plan and manage the sources of funds ( Financial planning and management), 8 ) ability to lead and think system ( Leadership and systems thinking / total system) [1].

While the need for soft skills possessed by graduates of public health education in public health education academic papers namely, (1) fear of God Almighty, (2) has a moral, ethical and good personality in completing its task, (3) act as citizens who take pride and patriotism and support for the peace of the world, (4) able to work together and have social sensitivity and concern towards society and the environment, (5) respect cultural diversity, views, beliefs, and religions as well as opinions / findings of the original another person, (6) upholding the rule of law and have the passion to put the interests of the nation and the wider public [1].

Public health graduate education is not free from problems. Problems of public health education in the curriculum according to the informants include public health institutions vary so it is not the same quality standards, the lack of professional teaching staff, public health books are not many, passive in pursuing science student, and campus facilities are inadequate.

"The need for filtering incoming students, as long as there is no filtering. The process must be good so that the output was good, with the graduates was so qualified, with that people will know Public Health Faculty. "(I7)

"If the lecturer is supposed to enter first grade must provide motivation, because the text book we can read it ourself, sometimes there are also people who need motivation to burn spirit. The material that it can be read, if you do not understand you can ask. Not only matter but support motivation "(I7) 
Solutions to the problems of education expressed include providing motivation to students on a regular basis about the essence of public health itself by faculty and student organizations, the need for quality improvement in the learning process so that any qualified graduates, need to improve the quality of teaching faculty, the need for screening when new admissions so the output will not be in vain. Students themselves need to be required to be more active in their studies. According to the informant as well for public health students themselves, trying hard to appropriating themselves and improve self-confidence that public health graduates are competent to work in accordance with the scientific field.

Performance or low performance can be caused by various factors that originate from inside and outside students. External factors can be learning facility, teaching faculty, and providing feedback system. Factor in student learning strategies include intelligence, motivation and so on. Teaching and learning process is a process that deliberately created for the benefit of students, so the students will be happy and excited to learn, teachers strive to provide and use all the potential and efforts [5].

The problem is the motivation issues/factors that are important for students. It means the students go to school/college without the motivation to learn. It is not just about motivation, it is highly variable in terms of the level and type, types, then the task of the teacher is to condition the potential motive was to concentrated on learning [5]. Walberg concludes that motivation contributes between 11 to 20 percent of learning achievement. Studies conducted by Suciati concluded that the contribution of motivation by 36 percent [6] while Mc . Clelland, suggests that achievement motivation ( achievement motivation ) have contributed 65 percent to the achievement of learning [5].

\subsection{The perception of the students about public health competency test}

According to the informant competency test is a measure of identity as a public health graduate , a tool that the public views that public health graduates were capable and competent. With the competency test expectations graduate job placement appropriate scientific public health later. This is in line with the Regulation of the Minister of Health No.1796 of 2011 concerning the Registration Medicals, competency testing is a form of quality assurance of higher education graduates health and competence of health workers in Indonesia organized by the educational unit accredited education provider or training institution is part of the quality assurance system and followed by mandatory learners, including adult education program, health professions candidates who have completed higher education health.

Specifically for health workers and medical personnel coupled with the registered obligation is one of the conditions to have a certificate of competency and to get participants are required to pass a competency test appropriate competency standards of their respective professions ${ }^{4}$. Competency test for Indonesian health workers who refer to the competency standards as agreed by stakeholders of their respective professions, covering aspects of knowledge, skills, and professional behavior are tested with test equipment in accordance with aspects of tested. Before following the competency test, participants had to get a briefing on professional education institutions each with a curriculum that is prepared in accordance with the standards of professional competence [4].

The quality of public health education is currently not measurable because it has not had formal education standard (the standard of care profession, descriptors, competency standards, curriculum standards, accreditation standards (quality cascade), or if there is still varied to meet the four pillars of action, consequently, increase number of public health education institute that much , not with the standardization of education and improvement of quality of education. These conditions is certainly not going to produce learning outcomes (learning outcomes) with the expected competencies, in order to answer the needs of the Public Health service quality in a professional manner .

\subsection{Student attitudes about public health competency test}

Informants have good interest to competency test because the informant had previously attended a seminar about the competency test conducted by the faculty. According to the informant competency test is important, and as a public health students have to prepare for it, and must be able to deal with it. With the competency test hope there is a clear job description for public health graduates.

Individuals with attitude trying to maximize the things wanted and unwanted. Individuals will form a positive attitude towards the things he felt would be profitable and form a negative attitude towards the things that she felt would be detrimental to. Attitude is a belief or opinion about the person, object or an idea. Attitude is a fixed pattern of tendencies feelings, beliefs and behavior of others, ideas and object [7].

IJPHS Vol. 3, No. 2, June 2014: $137-142$ 
"I think every people with public health background must know the information about competency test. " ( I7 )

Attitude contains several components, one component of cognitive or perceptual, informants in this study expressed a competency test should be widely disseminated in advance, it should be carefully prepared in advance with a lot of consideration, if the new 2015 is ripe can be done.

Attitude has several levels. The following are the various levels of attitudes, consisting of : ( 1 ) receiving ( Receiving ) mean that the person ( the subject ) and want to pay attention to a given stimulus ( objects ), ( 2 ) respond ( Responding ) provide an answer when asked, do nothing and accomplish tasks given is an indication of the attitude, ( 3 ) respect (Value), ( 4 ) encouraging others to work / discuss a problem is an indication of the attitude, ( 5 ) be responsible ( Responsible) is responsible for everything that has been chosen with an attitude all the risk is highest [4].

In this study, the informant has had levels above the stage to take responsibility for what has been selected. The informant did not hesitate to do the discussion and present their views to the researcher as well as to other informants enthusiastically without limitation suspicion or discomfort in the form of expression . The informant agreed with the concept of exit exam if the reason before graduation competency test conducted in academic stage, the institution will not be hands-off in the sense that they have a responsibility to the students who will participate competency test because its status is still a student, but if it is done after graduation the institution can wash its hands of the graduates.

According to the informant before maturity test student competency should really prepare , everything worked hard both students and lecturers. Another informant saw no positive effects and negative effects, the positive effects of a public health graduate clarity itself, and its negative effect is the lack of access to information concerning the competency test to students who are outside Java island .

The entire informants expect before maturity test student competency should really prepare, everything worked hard both students and lecturers. Another informant saw no positive effects and negative effects, the positive effects of a public health graduate clarity itself, and its negative effect is the lack of access to information concerning the competency test to students who are outside Java island.

Informants suggest the need for a try out and simulation before implementation of the competency test, so that students can prepare themselves. According to informants in welcoming competency test lecturers need to improve their competence first. Lecturers need to teach subjects sharp and detailed, and required a study club that is guided by the course lecturers. It should be also held training for faculty on effective teaching methods to support a national competency test.

\section{CONCLUSION}

From the results of research on the perceptions and attitudes of students about the profession and public health competency test at the Faculty of Public Health, Ahmad Dahlan University, can be summed up as follows:

1. There has been no public acknowledgment, job placement that is not in accordance with science, and graduate output related to the educational process undertaken during a student. If since the student lacks the soul of public health, less confident, less motivated and not serious in learning it when passed will have less competence so difficult to get a job or quality of performance as a public health personnel was not optimal .

2. Graduates need to know a lot of knowledge and have a good competence.

3. Student perceptions about the competency test as a means of proving the identity of that competent public health graduates. As a public health student should be able to face the competency test.

4. The competency test is important. All parties with a public health background to be aware of the existence of the competency test. The good competency test conducted before students graduate from university.

The small amount of subjects participated in this study could be the limitation of the study. Since this study was case study, so the result can not be generalized.

\section{REFERENCES}

[1] Indonesian Public Health Association, "Public Health Education - Academic Paper", 2012.

[2] Health Professional Education Quality Project, Directorate General of Higher Education, "Competency Test Development Institute - Academic Paper", pp. 2-3, 2012. 
[3] Rohayati I, "Peer Counseling to Increase Student's Self Confidence", Journal of Indonesian Education University, vol/issue: 7(1), 2011.

[4] Health Professional Education Quality Project, Directorate General of Higher Education, "Level of Student's Knowledge, Perceptions, and Attitudes Against Higher Health Education Competency Test in Indonesia", pp. 1-3, 2013.

[5] Abidin Z, "Motivation in Learning Strategy by ARCH Aproach", Scientific Paper of Muhammadiyah Surakarta University, SUHUF, vol/issue: XVIII(2), pp. 146, 2006.

[6] Suciati, "Learning Theory and Motivation", Directorate of Higher Education Departement of National Education, 2001.

[7] Coswanta Suyasa, "Attitudes Toward Organizational Culture and Organizational Comitment", Journal of Psychology Tarumanegara University, vol/issue: 2(1), pp. 3, 2004. 


\section{Student's Perception and Attitudes toward Public Health Profession and National Competency Examination}

1 fkm.unhas.ac.id Internet

75 words $-2 \%$

2 Triani Marwati, Siti Kurnia Widi Hastuti, Lina Handayani, Solikhah Solikhah, Lafi Munira.

47 words $-1 \%$ "Nosocomial Infection Prevention through Universal Precaution in Yogyakarta Muhammadiyah Hospital", International Journal of Public Health Science (IJPHS), 2016 Crossref

3 Dwi Fitria Ariyani, Lina Handayani. "Contribution Factors on Early Initiation of Breastfeeding", 46 words $-1 \%$ International Journal of Public Health Science (IJPHS), 2015 Crossref

4 uad.portalgaruda.org Internet

22 words $-1 \%$

5 Dilorom Abdullaevna Musakhodjeva, Marufjon Abidovich Yuldashev, Neqqadam Abdullaevich 17 words $-<1 \%$ Nuraliev, Rano Turdievna Sabitova et al. "Immunomodulatory Effects of Papain in Patients with Cervical Ectopies", International Journal of Public Health Science (IJPHS), 2014 Crossref

6 digilib.uns.ac.id Internet

11 words $-<1 \%$

7 Eirene Shinta Valevi, Lina Handayani. "Anxiety and 10 words $-<1 \%$ Family Support on Infected TORCH Patients", International Journal of Public Health Science (IJPHS), 2014 
8 iaesjournal.com

9 words $-<1 \%$

9 unpan1.un.org

8 words $-<1 \%$

10 fepafempafams.org

8 words $-<1 \%$ 